bubbles are visible to the operator when blood is drawn into the microcuvette. The most likely source of error, or misleading results, would be poor mixing of the full blood count sample before analysis. The distribution of "outliers" in fig 2 supports this assumption. An erroneously high or low haemoglobin result would be obtained no matter how often the same microcuvette was placed in the machine. The absence of high or low outliers in the HemoCue results performed in a laboratory (fig 1) may be explained because all laboratory samples were thoroughly mixed on a rotating rack before sampling. The health centre does not possess a sample mixer and the practice nurses rotate each full blood count tube by hand. If a $4 \mathrm{ml}$ whole blood sample were incorrectly mixed before withdrawal of a $10 \mu \mathrm{l}$ microcuvette sample then falsely high or low haemoglobin results would be obtained depending on which part of the original 4 $\mathrm{ml}$ sample was subsampled.

The results of this study emphasise how important it is to evaluate equipment intended for use in primary care within primary care by primary care staff. Practices considering using a HemoCue, or any similar portable haemoglobinometer, should also use a rotating mixer for samples. An alternative would be to incorporate some kind of mixer on the haemoglobinometer itself, or to restrict the use of the machine to samples obtained by the finger prick method alone. The operating instructions should also be modified to reflect the importance of this potential error. Probably if the HemoCue was operated by junior hospital staff in ward side rooms similar problems to those encountered by the health centre staff would occur.

I thank Mrs E Strachan, Mrs E Blacklaw, Drs D Dorward, J D E Knox, J A R Lawson, K L MacGregor, R F Scott, P E Turnbull, and A D Watson of Westgate Health Centre; Mr R King and Dr A S Todd of Ninewells Hospital and Medical School Haematology Laboratory, Dundee; Mr B Naidoo and Clandon Scientific Ltd for the loan of the HemoCue; and Mr R A Anderson, Mrs H Bulloch, Mrs F Robertson, and Miss A Scott of the Department of General Practice for statistical advice and secretarial help.

\section{References}

1 Vanzetti G. An azide-methemoglobin method for hemoglobin determination in blood. $\mathcal{f ~ L a b ~ C l i n}$ Med 1966;67:116-26.

2 Schenk $H$ von, Falkenson M, Lundberg B. Evaluation of "HemoCue," a new device for determining hemoglobin. Clin Chem 1985;31:4.

3 Bengtsson PG, Ronquist G, Holmgren C. New analytical system for the determination of hemoglobin at different levels in a primary health care district. Läkartidningen 1984;81:642-53.

4 Loose J, Southgate C, Raper CGL. Benefits of the portable haemoglobinometer in group practices. I $R$ Coll Gen Pract 1986;36:574-5.

Accepted 16 March 1987)

\title{
Appointment and mobility of general practitioners
}

\author{
CHRISTOPHER D SIDE
}

Changes in general practice partnerships are perceived as being undesirable; this, together with the current excess of doctors seeking practices over available vacancies, has caused a less than satisfactory procedure for selecting new principals to develop. This has reduced geographical mobility within general practice and resulted in increased personal stress and a lowering of morale. Consequently and paradoxically the likelihood of the partnership becoming unstable has increased.

\section{Changes in partnerships}

Most general practitioners who have been principals for seveal years have experienced a partnership change because of retirement, death, or, increasingly commonly, a break up of the partnership. Partnership changes are expensive and worrying for all parties. They are expensive to the partners because solicitors have to be employed when the lease or property ownership is changed and to vet partnership agreements. Additionally, accounting becomes complex, primarily because of the rather chaotic and uninformative manner in which family practitioner committees make their payments and because of tax allowances relating to individual partners. Partnership changes are also expensive to the newcomer, who will have to buy a house and will often have to buy into the practice. Changes are worrying because of anxieties within the partnership that the new partner may "rock the boat," and the newcomer may wonder whether he has done the right thing and whether his appointment will be confirmed after a probationary period. These difficulties naturally deter doctors from contemplating frequent changes and do not encourage mobility within the profession.

The Old Forge, Tring, Hertfordshire HP23 5AG

CHRISTOPHER D SIDE, BM, BCH, general practitioner

\section{Selection of new principals}

As partnership changes are known to be difficult it is perhaps surprising that more care is not taken in making a mutually beneficial appointment. No doubt the fact that it is at present a seller's market has contributed to the tendency to take short cuts in advertising and selection, but I suggest that these short cuts are undesirable.

It is not unusual for an advertisement to give only two items of information-for example, "vacancy in four doctor practice in London. Apply with curriculum vitae and two references to box XYZ." Sometimes useless information is added: "usual attached staff" is akin to advertising a house "with roof." In a January edition of Pulse 14 out of 26 advertisements used a box number. Such sparse practice details make it difficult to formulate a meaningful application, and the use of box numbers makes it virtually impossible for further information to be obtained. Local trainees obviously may have foreknowledge and therefore a distinct advantage. In one area in the west country virtually all new principals are selected from the local training scheme (personal communication). Thus geographical mobility is again discouraged and a doctor's decision on where to spend his working life is moved back to the time when he begins vocational training.

Not only does an uninformative advertisement make it difficult for the applicant but it inevitably results in a huge number of applications. In other words, the valuable device of "self selection" is not brought into play and the chances of selecting a candidate who has doubts is increased. It is far easier to deal with 20 applications from serious applicants than with 100 , many from doctors who might not want the job anyway.

Any selection process should begin with decisions about the type of person being sought. Some guidelines can be defined, but a complete description cannot be made; indeed, if too much detail is produced before selection there is a chance that no one will be found to fit the criteria and the person appointed will be considered to be second best. More importantly, the more applications the greater the perceived necessity to adhere rigidly to the criteria. This is also undesirable as suitable candidates may be passed over at an early stage of selection for some minor "fault."

Only three or four important points should be written down after long consideration and agreement by all the partners. Some characteristics-for example, the sex of the applicant-may be quite justifiable as a practice may wish to replace a retiring female partner with one of the same sex. Such an 
important requirement should be stated at the outset. Likewise a certain nationality or the ability to speak a certain language may be required, depending on the practice area. Considerable care, however, should be exercised in this. A recent amendment to the Sex Discrimination Act 1986, which came into force on 7 February this year, removed the exemption that previously applied to partnerships of fewer than six principals. It is now contrary to the act to discriminate on the grounds of sex (and race) either in an advertisement or at interview. Other criteria that are often chosen are difficult to justify - for example, that a candidate should not be divorced or already a principal in general practice (it seems illogical to put no value on experience). In a recent interview on Medikasset a doctor described his procedure for selecting a partner, when no applicant of principal status was considered. The reason given for this decision was that he did not have time to consider a doctor who for whatever reason was dissatisfied with his present lot. It could equally be argued that such candidates might have a much better idea of what they are looking for and more awareness of what factors would ensure a happy partnership in the future.

\section{Geographical mobility}

For reasons already stated it is now almost impossible for an established principal to change his practice. Even singlehanded practices are increasingly being offered to doctors fresh from a vocational training scheme. The inability to relocate has important implications that cannot be to the long term benefit of general practice in Britain.

Firstly, it has now become almost inevitable that when a doctor accepts a partnership he will have to remain there for the rest of his life. Thirty five years is a long time, and many things may change within the practice, environment, or family. Such inflexibility in employment is hard to find elsewhere in the Western world. In other professions, such as the law, a young solicitor may remain in his partnership for his working life but his family are not tied to living in a restricted area. Many accountants and solicitors travel $80 \mathrm{~km}$ to work, whereas most general practitioners have to live within $8 \mathrm{~km}$ of their surgeries.

Secondly, if a doctor is unhappy for professional or private reasons morale will wane and he will become less effective as a general practitioner with resulting deleterious effects on practice, family, and himself. When viewed on a national scale the lack of mobility must result in less than optimum contentment and performance within the profession. The knowledge that a move is unlikely to be achieved can only increase the risk of depression or alcohol abuse and subsequent decline in physical health. There is ample evidence that the impact of work on family life is a prime cause of anxiety and ill health among doctors. ${ }^{1-3}$

Apart from the inconvenience of partnership changes from the partners' point of view changes are said to be undesirable for the patients. The phrase "continuity of care" is mentioned without much thought. For most patients this has little meaning over long periods because $5-10 \%$ of a practice's population changes every year and in some practices, such as those in university towns, turnover may reach $30 \%$ a year. Patients change their doctor when they move around the country, and this generally presents few problems. Similarly, when there is a change of doctor in a partnership few patients will leave as a result and most quickly accept the new doctor. Surely continuity of care should not be used as a legitimate argument to prevent doctors moving around with as much freedom as their patients.

People usually find changes in their environment stimulating, and doctors are no exception. There may also be family reasons, such as aging parents, that would make a change of domicile desirable. Professionally a doctor might wish to develop new skills or interests that would necessitate a move: it would be difficult for him to work in an academic department if he practised at Land's End. Thus the ability to move within general practice would have many beneficial effects; in particular it would enhance the mental wellbeing of doctors and might eventually reduce the number of practices broken up.

\section{Rationalisation of advertising for vacancies}

To reduce some of the problems associated with selecting principals I suggest that a standardised approach is used. This would not be difficult to achieve as the mechanism already exists, although it is infrequently used. The partnership services department of the British Medical Association provides duplicated sheets that give more information than can be sensibly placed in the columns of the British Medical fournal. Initially information could be provided to the BMA on a standard form; the association could then place a short description containing essential information in the $B M \mathcal{F}$.An example might be: "Hightown. Four full time plus one part time. 12000 patients. Non-dispensing, urban health centre. Replacing full time male/female. Initially approximately $£ 17000$, parity three years. Information sheet XYZ." Doctors who were interested enough would then contact the BMA for the information sheet. These sheets would give detailed information; the table shows possible headings. On the basis of this résumé only serious applications would arrive at the practice; this would ease the task of shortlisting and increase the chance of a successful appointment.

\begin{tabular}{|c|c|}
\hline Size of practice & Number of partners and patients \\
\hline Location & Area and specific address \\
\hline Type & Rural/urban/mixed (some idea of spread) \\
\hline Patients & Class/nationality/occupations \\
\hline Practice accommodation & $\begin{array}{l}\text { Purpose built/house/health centre; private/rented; } \\
\text { common room/treatment room, etc; whether } \\
\text { applicant will have own room }\end{array}$ \\
\hline Equipment & $\begin{array}{l}\text { Electrocardiograph/audiometer/computer/age-sex } \\
\text { register }\end{array}$ \\
\hline Surgery arrangements & Appointment system, clinics \\
\hline Status & Teaching (postgraduate or undergraduate) \\
\hline Staff & Practice manager/nurses/counsellors \\
\hline Outside prots & $\begin{array}{l}\text { Industrial/clinical assistant and availability for } \\
\text { applicant }\end{array}$ \\
\hline Partners & Short biographical details \\
\hline Financial aira:lg nents & $\begin{array}{l}\text { Initial share, time to parity, current parity figure; } \\
\text { necessary investment required }\end{array}$ \\
\hline $\begin{array}{l}\text { Local informa: a } \\
\text { Applications }\end{array}$ & $\begin{array}{l}\text { House prices and schools, etc } \\
\text { Closing date/likely date of interview and start, etc. }\end{array}$ \\
\hline
\end{tabular}

Suggested information to be provided to prospective applicants for vacancies in general practice.

Such a procedure is used successfully in buying and selling houses but would differ here in that there would be only one agent concerned in a fairly small number of advertisements, usually less $\vec{\sigma}$ than 30 each week.

\section{References}

1 Cramond $w$. Anxiety in medical practice-the doctor's own anxiety. Aust NZ 7 Psychiatry 1969;3:324-8.

2 Ellard J. The disease of being a doctor. Med f Aust 1974;ii:318-23.

3 Evans J. Psychiatric illness in the physician's wife. Am J Psychiatry 1965;122:159-63.

(Accepted 13 March 1987)

\section{YEARS AGO}

We are glad to forget, amid the bright and almost overpowering rays of a July sun, the yellow smoke-laden fogs of a dull November day, but their reappearance under favourable climatic conditions is none the less sure, and it therefore behoves us to encourage the adoption of every means likely to diminish the virulence of an inevitable evil. The Smoke Abatement Exhibition of 1881, and the subsequent exertions of the Smoke Abatement Institute, have done much to stimulate the manufacture and to promote the 음 use of smokeless grates and kitcheners in our homes, and to emphasise the $N$ utility of the burning of smokeless fuel. With a view to rekindle the flagging o public interest in this important subject, an exhibition of smoke abating appliances has this week been opened at the Albert Palace, Battersea, by the Marquis of Lorne, who was accompanied by Mr. Ernest Hart, Sir Douglas $N$ Galton, Mr. Octavius Morgan, M.P., etc. His lordship, in the course of his $N$ remarks, spoke of the economy which attended the use of stoves which produced complete combustion, and the great waste of fuel which prevailed in this country as compared with some others he had visited. Mr. Ernest Hart called attention to the fact that great progress had been made since he and others had first taken this subject in hand, and that there was no manufacturing process which could not be carried on without the production of smoke. Fire-grates could now be had which would give from 20 to 30 per cent. more heat and $\mathbf{4 0}$ per cent. less smoke. He desired to see an Act passed $\stackrel{\mathbb{D}}{\Omega}$ to compel all factories and workshops, and even hotels, to be carried on $\mathbb{D}$ smokelessly. To effect the desired change they must bring home to the people the fact that the black pall and canopy of smoke, which shut out the sunlight and robbed every plant and human being in this great city of its due $ᄋ$ share of health and vitality, was in reality composed of some tons of solid coal, and arose from ignorance, extravagance, and malpractice on the part of the community. (British Medical fournal 1887;ii:82) 